\section{Risk factors for chronic non-communicable diseases and the CARMEN Initiative: a population-based study in the South of Brazil}

\author{
Fatores de risco para doenças crônicas \\ não-transmissíveis e a Iniciativa CARMEN: estudo \\ de base populacional no sul do Brasil
}

Marcelo Fernandes Capilheira 1

Iná S. Santos 1

Mario Renato Azevedo Jr. 1

Felipe Fossati Reichert 1,2

\footnotetext{
1 Programa de Pós-graduação em Epidemiologia, Universidade Federal de Pelotas, Pelotas, Brasil. 2 Departamento de Educação Física, Universidade Estadual de Londrina, Londrina, Brasil.

Correspondence M. F. Capilheira Programa de Pós-graduação em Epidemiologia Universidade Federal de Pelotas.

Rua Marechal Deodoro 1160, 3 o andar, Pelotas, RS 96020-220, Brasil. capilheira@brturbo.com.br
}

\begin{abstract}
The CARMEN Initiative is a strategy of the Pan American Health Organization and the World Health Organization that proposes populationbased interventions to reduce risk factors for chronic non-communicable diseases (CNCD) by approaching them simultaneously. The present study aims to provide a baseline for further interventions by the CARMEN Initiative based on a cross-sectional population-based study of 3,100 adults ( $\geq 20$ years old) in Pelotas, a city in the South of Brazil. Prevalence of smoking, physical inactivity, diabetes mellitus, hypertension, and excess weight were studied and presented separately and aggregated in various combinations. The most frequent risk factor was physical inactivity (73.2\%), followed by excess weight (48.1\%). Women were less active and thinner than men. More than half of the sample showed two or three risk factors (53.4\%). The combination of physical inactivity and excess weight was observed in $34.7 \%$ of the sample, while $10.8 \%$ presented physical inactivity, excess weight, and hypertension concurrently. The accumulation of risk factors for CNCD is frequent in the study population and the identification of the most common combinations is essential for planning future interventions.
\end{abstract}

Chronic Diseases; Risk Factors; Cross-Sectional Studies

\section{Introduction}

According to global estimates, mortality patterns have changed since the 1990s, with chronic non-communicable diseases (CNCD) exceeding communicable, maternal, and perinatal causes, except in Sub-Saharan Africa 1. Chronic diseases account for $59 \%$ of deaths in the world, principally cardiovascular diseases, diabetes, obesity, cancer, and respiratory diseases ${ }^{2}$. According to estimates for the year 2020, ischemic heart disease and stroke will become the main causes of morbidity and mortality in the world 3,4 .

In Brazil, in 2003 cardiovascular diseases accounted for $31 \%$ of all deaths from known causes, followed by cancer and external causes, approximately $15 \%$ each 5 . A population survey in 2002-2003 in 15 State capitals of Brazil and the Federal District 6 detected a high prevalence of the main risk factors for chronic diseases in the 15-69-year bracket: smoking, overweight/ obesity, and physical inactivity. The survey proposed to establish a baseline for dealing with the epidemic of chronic non-communicable diseases in the country, in keeping with the resolutions of the $26^{\text {th }}$ Pan-American Health Conference 7 and the 3rd Global Forum on the Prevention and Control of Chronic Non-Communicable Diseases, held in Brazil in 2003 8. However, knowledge of the prevalence of each single risk factor provides only a partial view of the problem, given that they frequently occur simulta- 
neously, with important implications for individual health 9,10. Studies in Salvador, Bahia 11, and Porto Alegre, Rio Grande do Sul 12, identified high prevalence rates for simultaneous cardiovascular risk factors.

Considering the theme's relevance and the need for immediate initiatives, the Pan-American Health Conference endorsed the recommendations of the 120th Meeting of the Executive Committee of the World Health Organization and developed four strategic lines of action to fight chronic non-communicable diseases: (1) the CARMEN Initiative (a Spanish-language acronym for Conjunto de Acciones para la Reducción Multifactorial de Enfermedades No Transmisibles, or Set of Actions for the Multifactorial Reduction of Non-Communicable Diseases) as the principal line of action; (2) surveillance of non-communicable diseases and risk factors; (3) innovations for responsible health services and chronic conditions; and (4) policy change advocacy. The Initiative also recommended that interventions consider the social context and the needs of different population groups 7 .

The CARMEN Initiative was developed in light of the experience and results of other programs: North Karelia, in Finland 13, and CINDI in various European countries and Canada 14. The main objective of the CARMEN Initiative is to improve the health status of populations in the Americas by reducing risk factors associated with chronic non-communicable diseases. The Initiative includes developing, implementing, and evaluating policies to reduce a set of common risk factors for chronic non-communicable diseases; promoting social mobilizations and population-based interventions; maintaining epidemiological surveillance of risk factors; and encouraging preventive practices that contribute to the reduction of health inequities. Brazil is currently advancing in the planning of the CARMEN Initiative, defining and completing a specific timetable for action 5 , like the inclusion of specific targets for fighting chronic non-communicable diseases within the National Health Promotion Policy of 200615

The current study aims to obtain a baseline for evaluating and monitoring risk factors for chronic non-communicable diseases in a medium-sized city, allowing assessment of the impact of future interventions. The idea is to verify the profile of the adult population in Pelotas, Rio Grande do Sul State, Brazil, as to the single and accumulated prevalence of the following factors: smoking, excess weight, physical inactivity, systemic arterial hypertension, and diabetes mellitus.

\section{Methodology}

The city of Pelotas is located in the far South of Brazil, with some 320 thousand inhabitants, 93\% of whom live in the urban area of the municipality 16 .

We designed a cross-sectional, populationbased study of adults ( $\geq 20$ years of age) residing in the urban area of the municipality. Institutionalized individuals or those incapable of completing the questionnaire were excluded from the study. The fieldwork was done from October to December 2003.

Sample size calculation used the expected prevalence rates for systemic arterial hypertension (20\%), diabetes mellitus (6\%), smoking $(22 \%)$, excess weight $(50 \%)$, and physical inactivity $(70 \%)$, with a $95 \%$ confidence level and allowable error of two percentage points. The final sample was increased by $10 \%$ for losses and refusals, resulting in 2,640 individuals.

Sample selection was based on data from the Brazilian population census for 2000 , conducted by the Brazilian Institute of Geography and Statistics (IBGE), and was done in two stages: selection of census tracts followed by selection of households. For each census tract in the city (total of 404), we obtained the mean income of heads of family and thus the mean income for each of the tracts, which were listed in increasing order of income. We then picked 144 census tracts by systematic draws.

In the second stage, all the households in each selected census tract were canvassed, identifying the inhabited households and business establishments. Based on the list of inhabited households, a systematic drawing was performed, proportional to the size, selecting an average of ten houses from each tract ( $\mathrm{n}=1,530$ households). These were canvassed by the researcher to deliver a letter of introduction, an invitation for the family to participate in the study, and clarifications, in addition to collecting information on the number, age, and gender of residents. These households were visited, and questionnaires were applied to all residents 20 years or older, by trained interviewers. The questionnaires were previously tested in a pilot study.

The interviewers were women with a minimum of complete secondary education, and had received specific training. They were not informed as to the study objectives or hypotheses. Approximately $10 \%$ of the interviews were redone with an abridged questionnaire, by supervisors, for quality control purpose. Data entry was performed with double keying-in, checking for inconsistencies and ranges, using Epi Info 6.04 (Centers for Disease Control and Prevention, Atlanta, USA). 
The independent socio-demographic variables were gender, age (in complete years), education (in complete years of schooling), skin color (classified as white and non-white, as observed by the interviewers), and economic class. The latter adopted the classification of the Brazilian Association of Opinion Poll Companies (ABEP), based on household durable consumer goods, having a full-time maid, and head-of-family's schooling. The ABEP classification categorizes individuals in economic classes $\mathrm{A}, \mathrm{B}, \mathrm{C}, \mathrm{D}$, and $\mathrm{E}$, from the richest to the poorest.

The health variables were:

a) Diabetes mellitus and systemic arterial hypertension based on reported medical diagnosis;

b) Smoking: defined as having smoked a least one cigarette a day for more than a month 17;

c) Excess weight: calculated according to body mass index as $\mathrm{kg} / \mathrm{m}^{2}$ (BMI). BMI was obtained by the interviewees' self-reported weight and height and calculated as weight $(\mathrm{kg})$ divided by height squared (square meters), categorized in two groups: normal weight $\left(\mathrm{BMI}<25 \mathrm{~kg} / \mathrm{m}^{2}\right)$ and excess weight $\left(\mathrm{BMI} \geq 25 \mathrm{~kg} / \mathrm{m}^{2}\right)$;

d) Physical inactivity: obtained by applying the section on leisure-time activity from the long version of the International Physical Activity Questionnaire (IPAQ) 18, defined individuals as sedentary when they practiced less than 150 minutes of physical activity in a normal week. Weekly physical activity score was based on the time spent in vigorous activities, multiplied by two. The criterion adopted for the current study follows current recommendations for practicing physical activities to obtain health benefits 19 .

The descriptive analyses used Stata 9.0 (Stata Corp., College Station, USA). The results with a $\mathrm{p}$ value for statistical significance were obtained using the Wald test for heterogeneity and linear trend (ordinal variables), setting significance at $5 \%$. The analyses took design effect into consideration, using the set of "survey" commands from Stata 9.0.

The research project was approved by the Institutional Review Board of the School of Medicine at the Federal University in Pelotas.

\section{Results}

Among the 1,530 households visited, 3,214 individuals were considered eligible for the study. Of these, 3,100 were interviewed, with losses and refusals totaling $3.5 \%(\mathrm{~N}=114)$. Information on excess weight was not available for 381 individuals, who were unable to inform their own height. The variables that combined excess weight with other risk factors showed a maximum of 394 missing values. The maximum number of cases of missing information was 16 for socio-demographic variables (socioeconomic status) and 10 for health variables (physical inactivity).

The sample was predominantly female (56.7\%), white $(81 \%)$, and from socioeconomic classes D and E (41.9\%). Slightly more than onefourth of the sample (26.2\%) had zero to four years of schooling. Mean age was 43.2 years $(\mathrm{SD}=$ 16.1), varying from 20 to 92.

Table 1 shows the overall prevalence and gender stratification for the independent health risk factors. Physical inactivity showed the highest prevalence $(73.2 \%)$, and was more common in women than in men $(\mathrm{p}<0.001)$. Excess weight was the second most prevalent factor, found in approximately half the sample, with men showing a higher prevalence than women $(\mathrm{p}<0.001)$. Smoking was more prevalent among men $(\mathrm{p}=$ 0.009 ), while women showed a higher prevalence of reported hypertension $(\mathrm{p}=0.006)$. Prevalence of medically diagnosed diabetes mellitus did not differ significantly between men and women.

Table 2 provides the accumulated risk of chronic non-communicable diseases. More than half the sample (53.4\%) showed two or three risk factors, with no difference between men and women.

Table 3 describes the prevalence of two combined risk factors in the total sample and by gender. For both men and women, the combination of physical inactivity and excess weight showed the highest prevalence. In men, the second most prevalent combination of risk factors was physical inactivity and smoking (22.8\%), as compared to physical inactivity and hypertension in women $(21.6 \%)$.

Table 4 provides the combinations of three concurrent risk factors. In men, the simultaneous

Table 1

Prevalence of health risk factors in the overall sample and stratified by gender. Pelotas, Rio Grande do Sul State, Brazil, 2003.

\begin{tabular}{lccc}
\hline Risk factors & Overall & \% & \\
& $(\mathbf{N}=3,100)$ & $\begin{array}{c}\text { Men } \\
(\mathbf{n}=1,344)\end{array}$ & $\begin{array}{c}\text { Women } \\
(\mathbf{n}=\mathbf{1 , 7 5 6 )}\end{array}$ \\
\hline Systemic arterial hypertension & 23.4 & 18.2 & 27.4 \\
Diabetes mellitus & 6.3 & 5.4 & 7.0 \\
Excess weight * & 48.1 & 53.6 & 43.3 \\
Physical inactivity & 73.2 & 67.0 & 78.0 \\
Smoking & 26.7 & 31.3 & 23.1 \\
\hline
\end{tabular}

* Largest number of missing values $(n=381)$. 
Overall and gender-stratified prevalence of accumulated risk factors for chronic non-communicable diseases. Pelotas, Rio Grande do Sul State, Brazil, 2003.

\begin{tabular}{|c|c|c|c|c|c|c|}
\hline \multirow[t]{2}{*}{ Number of risk factors } & \multicolumn{2}{|c|}{$\begin{array}{c}\text { Overall } \\
(\mathrm{N}=2,706) \text { * }\end{array}$} & \multicolumn{2}{|c|}{$\begin{array}{c}\text { Men } \\
(n=1,272)\end{array}$} & \multicolumn{2}{|c|}{$\begin{array}{c}\text { Women } \\
(n=1,434)\end{array}$} \\
\hline & $\%$ & $\mathrm{n}$ & $\%$ & $95 \% \mathrm{Cl}$ & $\%$ & $95 \% \mathrm{Cl}$ \\
\hline 0 & 10.1 & 272 & 10.5 & $8.6-12.7$ & 9.7 & $8.1-11.6$ \\
\hline 1 & 32.2 & 871 & 30.4 & $27.7-33.1$ & 33.8 & $31.4-36.3$ \\
\hline 2 & 36.7 & 992 & 37.7 & $34.9-40.5$ & 35.8 & $33.3-38.4$ \\
\hline 3 & 16.7 & 451 & 17.2 & $15.3-19.3$ & 16.2 & $14.5-18.0$ \\
\hline 4 & 4.0 & 109 & 3.8 & $2.9-5.0$ & 4.3 & $3.3-5.5$ \\
\hline 5 & 0.4 & 11 & 0.6 & $0.3-1.1$ & 0.3 & $0.1-0.7$ \\
\hline
\end{tabular}

* The combinations of risk factors generated 394 missing values.

Table 3

Combination of health risk factors among individuals with two concurrent factors. Pelotas, Rio Grande do Sul State, Brazil, 2003.

\begin{tabular}{|c|c|c|c|}
\hline \multirow[t]{2}{*}{ Combined Factors } & \multicolumn{3}{|c|}{$\%$} \\
\hline & $\begin{array}{c}\text { Overall } \\
(\mathrm{N}=3,100)\end{array}$ & $\begin{array}{c}\text { Men } \\
(n=1,344)\end{array}$ & $\begin{array}{c}\text { Women } \\
(n=1,756)\end{array}$ \\
\hline Physical inactivity + excess weight * & 34.7 & 36.8 & 32.7 \\
\hline Physical inactivity + smoking & 20.8 & 22.8 & 19.2 \\
\hline Physical inactivity + systemic arterial hypertension & 17.8 & 12.9 & 21.6 \\
\hline Physical inactivity + diabetes mellitus & 5.0 & 4.1 & 5.7 \\
\hline Excess weight + smoking & 10.9 & 14.2 & 8.0 \\
\hline Excess weight + systemic arterial hypertension & 14.7 & 13.0 & 16.2 \\
\hline Excess weight + diabetes mellitus & 4.0 & 4.0 & 4.0 \\
\hline Smoking + systemic arterial hypertension & 5.1 & 5.1 & 5.1 \\
\hline Smoking + diabetes mellitus & 1.3 & 1.4 & 1.3 \\
\hline Systemic arterial hypertension + diabetes mellitus & 4.1 & 2.8 & 5.1 \\
\hline
\end{tabular}

* Largest number of missing values $(n=388)$.

presence of physical inactivity, excess weight, and smoking showed the highest prevalence $(10.6 \%)$. In women, the most frequent combination was physical inactivity, excess weight, and hypertension $(11.9 \%)$.

All the possible combinations of four concurrent factors were explored, and none showed prevalence greater than $2.5 \%$ (in this case, excess weight, hypertension, diabetes mellitus, and physical inactivity in women).

Prevalence of all the single risk factors increased with age, with statistical significance for linear trend. Figure 1 shows the prevalence of physical inactivity and other combined factors according to age. Physical inactivity, the single most prevalent risk factor in the sample, showed a clear upward trend with age $(\mathrm{p}<0.001)$. Likewise, physical inactivity plus excess weight, the most prevalent combination of two concurrent factors, showed a positive association with age ( $p<0.001)$. The most prevalent combination of three factors (physical inactivity, excess weight, and hypertension) was also directly related to age $(\mathrm{p}<0.001)$

\section{Discussion}

The CARMEN Initiative recommends population-based interventions to simultaneously reduce and prevent the principal risk factors for chronic non-communicable diseases. The popu- 
Combination of health risk factors among individuals with three concurrent factors. Pelotas, Rio Grande do Sul State, Brazil, 2003.

\begin{tabular}{|c|c|c|c|}
\hline \multirow[t]{2}{*}{ Combined Factors } & \multicolumn{3}{|c|}{$\%$} \\
\hline & $\begin{array}{c}\text { Overall } \\
(\mathrm{N}=3,100)\end{array}$ & $\begin{array}{c}\text { Men } \\
(n=1,344)\end{array}$ & $\begin{array}{c}\text { Women } \\
(n=1,756)\end{array}$ \\
\hline Physical inactivity + excess weight + smoking & 8.2 & 10.6 & 6.1 \\
\hline Physical inactivity + excess weight + systemic arterial hypertension* & 10.6 & 9.2 & 11.9 \\
\hline Physical inactivity + excess weight + diabetes mellitus & 3.2 & 3.2 & 3.2 \\
\hline Physical inactivity + smoking + systemic arterial hypertension & 4.2 & 4.0 & 4.4 \\
\hline Physical inactivity + smoking + diabetes mellitus & 1.0 & 1.1 & 1.0 \\
\hline Physical inactivity + systemic arterial hypertension + diabetes mellitus & 3.3 & 2.2 & 4.1 \\
\hline Excess weight + smoking + systemic arterial hypertension & 2.9 & 3.3 & 2.5 \\
\hline Excess weight + smoking + diabetes mellitus & 0.7 & 1.0 & 0.5 \\
\hline Excess weight + systemic arterial hypertension + diabetes mellitus & 2.7 & 2.2 & 3.2 \\
\hline Smoking + systemic arterial hypertension + diabetes mellitus & 0.8 & 0.8 & 0.9 \\
\hline
\end{tabular}

* Largest number of missing values $(n=393)$.

Figure 1

Prevalence of physical inactivity and combined risk factors by age. Pelotas, Rio Grande do Sul State, Brazil, 2003.

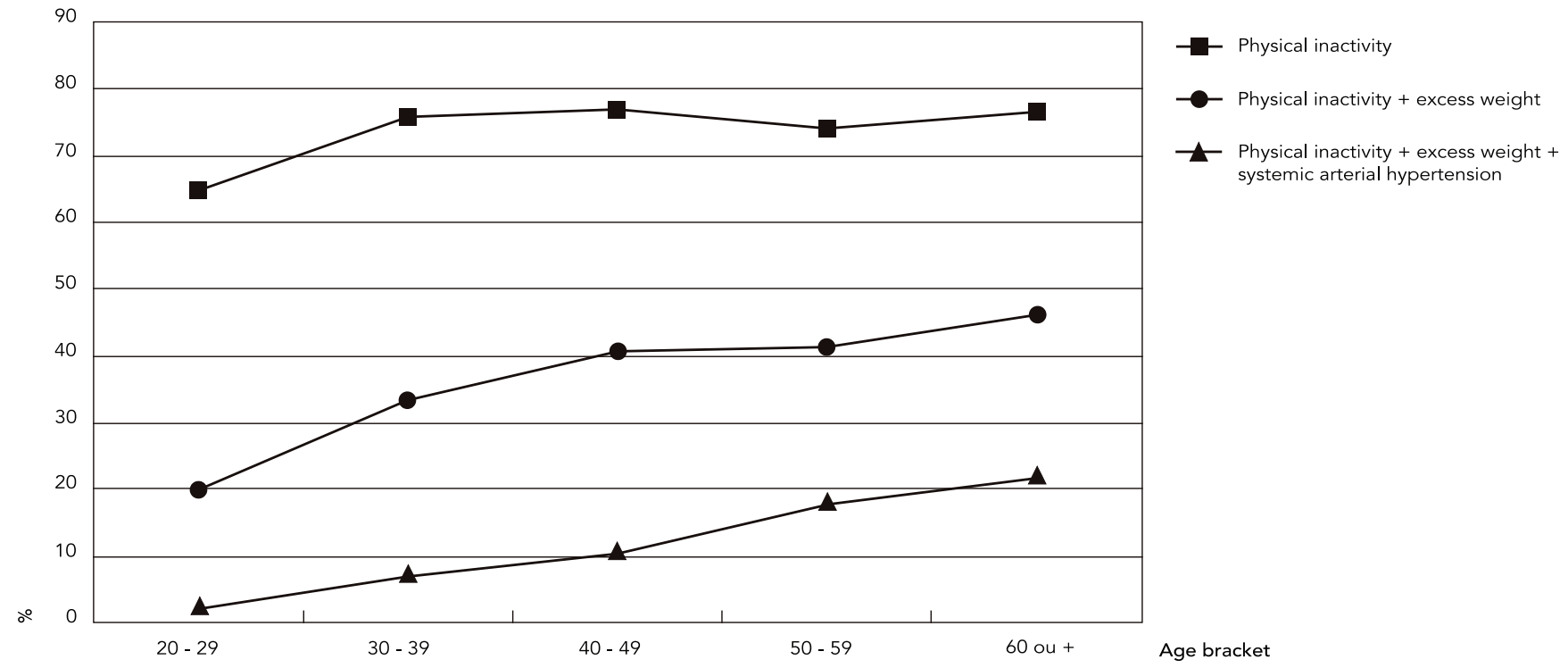

lation-based strategy has been recommended based on evidence that individual interventions have limited sustainability and low impact on the population 14,20 .

The current study meets the demand by the CARMEN Initiative to provide information on risk factors for chronic non-communicable diseases in order to support and monitor subsequent interventions. In addition, as a population-based study, it furnishes representative information on the adult population in Pelotas, the third largest city in the State of Rio Grande do Sul 16. It fur- 
ther highlights the importance of cross-sectional studies for public health evaluations, furnishing rapid, low-cost information on various links in the causal chain of collective phenomena 21,22,23.

However, one limitation is the fact that direct measurements were not taken for the subjects' blood pressure, blood glucose, weight, and height. However, the single prevalence rates for hypertension, diabetes mellitus, and excess weight were similar to those reported elsewhere in the Brazilian literature 6,12.

A major portion of the literature describes the prevalence of single risk factors for chronic non-communicable diseases, which is relevant for monitoring. However, it is necessary to complement such information with prevalence rates for accumulated risks, given that in medical practice, various protocols use accumulated risk factor scores for establishing routine management. The $5^{\text {th }}$ Brazilian Guidelines on Arterial Hypertension 9 recommend risk stratification based (among other things) on the number of accumulated risk factors. Likewise, a publication by the Brazilian Ministry of Health 10 in 2006 highlights the importance of global risk evaluation for chronic cardiovascular, cerebrovascular, and renal diseases, rather than evaluations of single risk factors.

Approximately $40 \%$ of the adult population in the city of Pelotas have two of the risk factors, and the most prevalent combination was physical inactivity and excess weight, followed by physical inactivity and smoking. The occurrence of two or more risk factors was present in $57.8 \%$ of subjects (59.4\% and $56.6 \%$ in men and women, respectively). A study in Porto Alegre in the State of Rio Grande do Sul 12 found a 39\% prevalence rate for two or more risk factors, with physical inactivity and smoking as the most frequent combination in both men and women. A study in Salvador, Bahia State 11 identified $69 \%$ and $68.1 \%$ of two or more accumulated risk factors in men and women, respectively. The higher prevalence rates in the study in Salvador may be due to the fact that the information was not self-reported, but obtained through direct measurements. Still, as mentioned above, the prevalence rates found in the current study are close to those in the international literature $6,12,24$.

Physical inactivity was the most prevalent risk factor in the study population, similar to the findings of a study in Chile (84.6\%) 25 and two studies in Porto Alegre, in the late 1990s 24 (71.3\%) and late 1980s 12 (69\% and $82 \%$ for men and women, respectively). In addition, women were more sedentary, in agreement with the current literature 6,12,23

The combination of physical inactivity and excess weight may be related to the pace of modern life: stress, increased consumption of highsugar and high-fat industrially processed foods, and decreased physical activity ${ }^{2}$. Physical inactivity showed a high prevalence in the younger population $(64.9 \%)$ and increased slightly with age. The trend was even sharper when other factors were associated with physical inactivity. Thus, interventions aimed at reducing physical inactivity should be targeted with the same intensity to older individuals as to younger ones.

The older population shows a higher prevalence of accumulated risk factors, and a higher probability of presenting controllable (but not reversible) conditions like hypertension and diabetes mellitus ( $47.1 \%$ and $13.8 \%$, respectively, in the 60 and older age bracket). Thus, interventions in this population group should mainly adopt secondary measures to prevent death from chronic non-communicable diseases, like controlling blood pressure and blood sugar. Interventions in younger populations should approach primary preventive measures, like the adoption of a less sedentary lifestyle and healthier eating habits, given that, in addition to physical inactivity, the 20-29-year age bracket showed the highest prevalence of excess weight (30.2\%). Obviously, both types of preventive measures should be adopted, but they could have a more specific focus according to evidence of accumulated risk factors by age bracket.

Finally, the findings presented here are consistent with the literature as to accumulated risk factors and contribute to the identification of the most prevalent combinations. It thus becomes possible to formulate strategies to fight chronic non-communicable diseases, prioritizing the most frequent groups of factors in the population. Through comprehensive community interventions, simultaneously approaching the most prevalent combinations of risk factors, it is possible to positively impact the epidemic of chronic non-communicable diseases in the Americas. 


\section{Resumo}

A Iniciativa CARMEN é uma estratégia da Organização Pan-Americana da Saúde e da Organização Mundial da Saúde de combate às doenças crônicas não-transmissíveis, que prevê intervenções populacionais para a redução simultânea de seus fatores de risco. Pretende-se fornecer uma linha de base para intervenções da Iniciativa CARMEN valendo-se de um estudo de base populacional com 3.100 adultos ( $\geq 20$ anos), moradores de Pelotas, Rio Grande do Sul. Os fatores estudados foram: tabagismo, sedentarismo, diabetes mellitus, hipertensão arterial sistêmica e excesso de peso, sendo descritos acumulados, isoladamente e em combinações. O sedentarismo foi o fator de risco mais prevalente (73,2\%), seguido do excesso de peso (48,1\%). As mulheres foram mais sedentárias e mais magras que os homens. Mais da metade da população apresenta dois ou três fatores de risco (53,4\%). A combinação de sedentarismo e excesso de peso ocorreu em $34,7 \%$ da amostra; e sedentarismo, excesso de peso e hipertensão, em 10,8\%. O acúmulo de fatores de risco para doenças crônicas não-transmissíveis é freqüente na população estudada e a identificação das suas combinações mais prevalentes é de grande relevância para o planejamento de intervenções futuras.

Doenças Crônicas; Fatores de Risco; Estudos Transversais

\section{References}

1. Pan American Health Organization. New noncommunicable diseases program at PAHO: the global and regional predominance of non-communicable diseases. Epidemiol Bull 1995; 16:6-8

2. Organização Pan-Americana da Saúde. Doenças crônico-degenerativas e obesidade: estratégia mundial sobre alimentação saudável, atividade física e saúde. Brasília: Organização Pan-Americana da Saúde; 2003.

3. Beaglehole R, Yach D. Globalisation and the prevention and control of non-communicable disease: the neglected chronic diseases of adults. Lancet 2003; 362:903-8.

4. World Health Organization. The World Health Report 2003: reducing risks promoting healthy life. Geneva: World Health Organization; 2002.

5. Ministério da Saúde. A vigilância, o controle e a prevenção das doenças crônicas não-transmissíveis: doenças crônicas não-transmissíveis no contexto do Sistema Único de Saúde brasileiro. Brasília: Ministério da Saúde/Organização Pan-Americana da Saúde; 2005.

\section{Contributors}

M. F. Capilheira, M. R. Azevedo, and F. F. Reichert conducted the analyses and wrote the first version of the manuscript. I. S. Santos reviewed the manuscript and introduced modifications in the final version.
6. Ministério da Saúde. Inquérito domiciliar sobre comportamentos de risco e morbidade referida de doenças e agravos não-transmissíveis: Brasil, 15 capitais e Distrito Federal, 2003-2004. Rio de Janeiro: Instituto Nacional de Câncer; 2004.

7. Organização Pan-Americana da Saúde/Organização Mundial da Saúde. 26a Conferência Sanitária Pan Americana. http://www.paho.org/portu guese/gov/csp/csp26-4-p.pdf (accessed on 10/ Feb/2007).

8. World Health Organization. The Report of the III Global Forum on NCD Prevention and Control. Geneva: World Health Organization; 2004.

9. Sociedade Brasileira de Cardiologia/Sociedade Brasileira de Hipertensão/Sociedade Brasileira de Nefrologia. V diretrizes brasileira de hipertensão arterial 2006. http://www.sbh.org.br/documen tos/index.asp (accessed on 10/Feb/2007).

10. Ministério da Saúde. Prevenção clínica de doenças cardiovasculares, cerebrovasculares e renais. Brasília: Ministério da Saúde; 2006. 
11. Lessa I, Araújo MJ, Magalhães L, Almeida Filho N, Aquino E, Costa MCR. Simultaneidade de fatores de risco cardiovascular modificáveis na população adulta de Salvador (BA), Brasil. Rev Panam Salud Pública 2004; 16:131-7.

12. Duncan BB, Schmidt MI, Polanczyk CA, Homrich CS, Rosa RS, Achutti AC. Fatores de risco para doenças não-transmissíveis em área metropolitana na região sul do Brasil. Prevalência e simultaneidade. Rev Saúde Pública 1993; 27:143-8.

13. Puska P, Vartiainen E, Tuomilehto J, Salomaa V, Nissinen A. Changes in premature deaths in Finland: successful long term prevention of cardiovascular diseases. Bull World Health Organ 1998; 76:419-25.

14. Pan-American Health Organization. CARMEN: an initiative for integrated prevention of non-communicable diseases in Americas. Washington DC: Pan-American Health Organization; 2003.

15. Ministério da Saúde. Política nacional de promoção a saúde. Brasília: Secretaria de Atenção a Saúde, Ministério da Saúde; 2006.

16. Instituto Brasileiro de Geografia e Estatística. Censo demográfico 2000. Rio de Janeiro: Instituto Brasileiro de Geografia e Estatística; 2001.

17. World Health Organization. Definitions of smoking. Global link. Geneva: World Health Organization; 2003.
18. Craig CL, Marshall AL, Sjostrom M, Bauman AE, Booth ML, Ainsworth BE, et al. International Physical Activity Questionnaire: 12-country reliability and validity. Med Sci Sports Exerc 2003; 35:1381-95.

19. Pate RR, Pratt M, Blair SN, Haskell WL, Macera CA, Bouchard C, et al. A recommendation from the Centers for Disease Control and Prevention and the American College of Sports Medicine. JAMA 1995; 273:402-7.

20. Rose G. Sick individuals and sick populations. Int J Epidemiol 2001; 30:427-32.

21. Black N. Why we need observational studies to evaluate the effectiveness of health care. BMJ 1996; 312:1215-8.

22. Santos IS, Victora CG. Serviços de saúde: epidemiologia, pesquisa e avaliação. Cad Saúde Pública 2004; 20 Suppl 2:S337-41.

23. Victora CG, Habitch JP, Bryce J. Evidence-based public health: moving beyond randomized trials. Am J Public Health 2004; 94:400-5.

24. Gus I, Fischmann A, Medina A. Prevalence of risk factors for coronary artery disease in the Brazilian state of Rio Grande do Sul. Arq Bras Cardiol 2002; 78:484-90.

25. Jadue L, Veja J, Escobar MC, Delgado I, Garrido C, Lastra P, et al. Risk factors for chronic noncommunicable diseases: methods and results of CARMEN program basal survey. Rev Méd Chile 1999; 127:1004-13.

Submitted on $05 / \mathrm{Mar} / 2007$

Final version resubmitted on 18/Sep/2007 Approved on 13/Nov/2007 